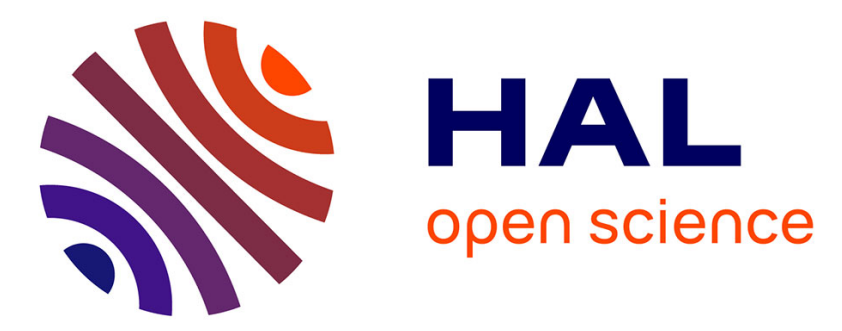

\title{
Evidence for quasi-static scission configurations obtained from long range particle accompanied fission distributions
}

\author{
C. Guet, C. Signarbieux, P. Perrin, H. Nifenecker, B. Leroux, M. Asghar
}

\section{- To cite this version:}

C. Guet, C. Signarbieux, P. Perrin, H. Nifenecker, B. Leroux, et al.. Evidence for quasi-static scission configurations obtained from long range particle accompanied fission distributions. Journal de Physique Lettres, 1978, 39 (13), pp.213-215. 10.1051/jphyslet:019780039013021300 . jpa-00231481

\author{
HAL Id: jpa-00231481 \\ https://hal.science/jpa-00231481
}

Submitted on 1 Jan 1978

HAL is a multi-disciplinary open access archive for the deposit and dissemination of scientific research documents, whether they are published or not. The documents may come from teaching and research institutions in France or abroad, or from public or private research centers.
L'archive ouverte pluridisciplinaire HAL, est destinée au dépôt et à la diffusion de documents scientifiques de niveau recherche, publiés ou non, émanant des établissements d'enseignement et de recherche français ou étrangers, des laboratoires publics ou privés. 


\title{
EVIDENCE FOR QUASI-STATIC SCISSION CONFIGURATIONS OBTAINED FROM LONG RANGE PARTICLE ACCOMPANIED FISSION DISTRIBUTIONS
}

\author{
C. GUET, C. SIGNARBIEUX $\left({ }^{*}\right)$, P. PERRIN $\left({ }^{* *}\right)$, H. NIFENECKER $\left({ }^{* *}\right)$, \\ B. LEROUX $(* * *)$ and M. ASGHAR
}

Institut Laue-Langevin, 156X Centre de Tri, 38042 Grenoble Cedex, France

(Reçu le 27 avril 1978, accepté le 18 mai 1978)

\begin{abstract}
Résumé. - De nouveaux résultats sur la fission accompagnée de particules légères de ${ }^{236} \mathrm{U}$ sont présentés. Les largeurs de la distribution angulaire de la particule $\alpha$ sont les mêmes dans les fissions $\mathrm{de}^{236} \mathrm{U}\left(\mathrm{n}_{\mathrm{th}}\right)$ et de ${ }^{252} \mathrm{Cf}$ (s.f). Il apparaît que cette largeur angulaire est une fonction décroissante de l'énergie cinétique totale des fragments de fission. Ces résultats suggèrent que les caractéristiques de ce mode de fission ne sont pas incompatibles avec un modèle de la scission supposant l'équilibre thermodynamique des degrés de liberté collectifs.

Abstract. - New experimental results on light-particle-accompanied neutron-induced fission of ${ }^{236} U$ are presented. The widths of the $\alpha$-particle angular distributions are the same for ${ }^{236} U\left(n_{t h}\right)$ and ${ }^{252} \mathrm{Cf}$ (s.f). This angular width appears to be a decreasing function of the total fission fragment kinetic energy. These results suggest that the characteristics of this mode of fission are not inconsistent with a semi-equilibrium model for scission.
\end{abstract}

The knowledge of the fragment shapes and kinetic energies at scission is essential for any dynamical theory of fission. Since light charged particles emitted in ternary fission emerge from the neck joining the nascent fragments at a time close to scission, a detailed study of this mode of fission should provide unique information on the last stage of the fission process and more generally on the dynamical properties of nuclear matter at low and moderate temperatures. However, the extraction of scission parameters from ternary fission data is unfortunately not straightforward. As we are confronted with a three-body problem, the simplest procedure is to try a set of initial conditions which could be identified with the scission parameters, to compute the trajectories [1], and to compare the calculated quantities at infinity with the experimental data. By scission parameters we mean essentially the prescission kinetic energy $E_{\mathbf{K}_{0}}$ of the fission fragments, the initial momentum of the $\alpha$-particle and their relative positions. $E_{\mathrm{K}_{0}}$ is the kinetic energy acquired in the fission mode during the descent from saddle to scission.

(*) Centre d'Etudes Nucléaires, DPhN/MF, BP 2, 91190 Gif sur Yvette, France.

(**) Centre d'Etudes Nucléaires, DRF/CPN, 85X, 38041 Grenoble, France.

(***) Université de Bordeaux, Gradignan, France.
The results which are presented below may provide new information on the sharing between potential and kinetic energies during the descent from saddle to scission. These new features of $\alpha$-accompanied neutron induced fission of ${ }^{236} \mathrm{U}$ have been obtained recently in an experiment carried out at the Grenoble High Flux Reactor where a beam of $5.5 \times 10^{9} \mathrm{n}_{\mathrm{th}} / \mathrm{cm}^{2} / \mathrm{s}$ is available. The angular distribution of the $\alpha$-particles was measured with a good accuracy as a function of the kinetic energy and mass of the fission fragments. A silicon rectangular detector $(1 \mathrm{~cm} \times 3 \mathrm{~cm})$ fixed the $\alpha$ direction while 7 circular $\left(\pi \mathrm{cm}^{2}\right)$ fission detectors were placed at angles from $68^{\circ}$ to $98^{\circ}$ with respect to the $\alpha$ direction in steps of $5^{\circ}$. The $1 \mathrm{~cm}^{2}$ circular uranium target was $150 \mu \mathrm{g} / \mathrm{cm}^{2} \mathrm{UF}_{4}\left({ }^{235} \mathrm{U}\right.$ enrichment of $97 \%$ ) evaporated on to a $20 \mu \mathrm{g} / \mathrm{cm}^{2}$ VYNS backing. The experimental set-up allowed for a geometrical angular dispersion (FWHM) of $5^{\circ}$, and for a mass dispersion (FWHM) of $6 \mathrm{amu}$. The mass of the fission fragment was determined by measuring its kinetic energy and velocity, this last quantity being derived from the difference of times-of-flight of fission fragment and $\alpha$ particle after appropriate corrections.

A large number of correlations have been derived and will be presented in a detailed publication. We present here two of these results which we believe deserve special attention : 
a) The widths of the global $\alpha$-particle angular distributions are nearly identical for ${ }^{236} U\left(n_{t h}\right)$ and ${ }^{252} \mathrm{Cf}$ (sf).

The angular distribution is defined with respect to the light fragment direction. Its most probable value and width depend slightly upon the $\alpha$ energy threshold below which the events are rejected. The most probable angle, $81.3^{\circ} \pm 0.4$ for particles with kinetic energy higher than $10 \mathrm{MeV}\left(82^{\circ} \pm 0.4\right.$ for $\left.E_{\alpha}>12.5 \mathrm{MeV}\right)$ is lower by about $2^{\circ}$ than the angle measured for ${ }^{252} \mathrm{Cf}(\mathrm{sf})[2,3]$. This difference is easily understandable in terms of the more asymmetric ratio of the mean fragments masses for ${ }^{236} \mathrm{U}$ than for ${ }^{252} \mathrm{Cf}$; this leads to a stronger deflection away from the perpendicular direction for ${ }^{236} \mathrm{U}$. After correction of the geometrical dispersion, the width (FWHM) of the distribution is $18.7^{\circ} \pm 0.8^{\circ}$ for $E_{\alpha}>10 \mathrm{MeV}$. This width is lower than those measured previously [4]. We want to underline the striking similarity between this value and $18.5^{\circ} \pm 1^{\circ}$ (FWHM) measured for ${ }^{252} \mathrm{Cf}[2,3]$.

In so far as the classical three-point-charge model is valid, these present observations disfavour the dynamical liquid drop treatment of fission proposed by Nix et al. [5, 6]. In addition to high pre-scission kinetic energies (around $25 \mathrm{MeV}$ for ${ }^{236} \mathrm{U}$ ), the liquid drop calculations predict a marked increase of this quantity as a function of the fissibility parameter. For example, the pre-scission kinetic energy for ${ }^{252} \mathrm{Cf}$ is predicted to be about 1.5 times of the value for ${ }^{236} \mathrm{U}$. Since the final angular distribution of the $\alpha$-particles is essentially dependent on their initial positions and the initial fragment kinetic energy [1,7], one should expect a wider angular spectrum for ${ }^{252} \mathrm{Cf}$ than for ${ }^{236} \mathrm{U}$ which is contrary to the experimental results. In order to reproduce such global angular widths, trajectory calculations have shown that with reasonable dispersions of initial parameters, one cannot rule out the possibility of low initial fragment kinetic energy $\left(E_{\mathrm{K}_{0}}<10 \mathrm{MeV}\right)[7,8]$.

b) The angular distribution gets narrower as the kinetic energy of the fission fragments increases.

In figure 1 we show the dependence of the average angle $\left\langle\theta_{\alpha-\mathrm{L}}\right\rangle$ and the angular width (FWHM) upon the total kinetic energy $E_{\mathrm{K}}$ of the fission fragments for given values of fragment mass and for $\alpha$-kinetic energies higher than $10 \mathrm{MeV}$. The average angle does not show any significant variation with $E_{\mathrm{K}}$. However, there is a clear decrease of the width as $E_{\mathrm{K}}$ goes up. In order to preclude the effect of the well-known anticorrelation between $E_{\alpha}$ and $E_{\mathrm{K}}[9,10]$, the angular distribution was derived after setting a narrow window $(2 \mathrm{MeV})$ on the $\alpha$-energy spectrum. The same trend was observed : the angular distribution is narrower for higher fragment energy events. It is generally accepted that the final $\alpha$-kinetic energy is strongly determined by its initial value $E_{\alpha_{0}}[1]$. Therefore, for a given final $\alpha$-kinetic energy (hence a small spread in $E_{\alpha_{0}}$ ), the equation for variances derived from
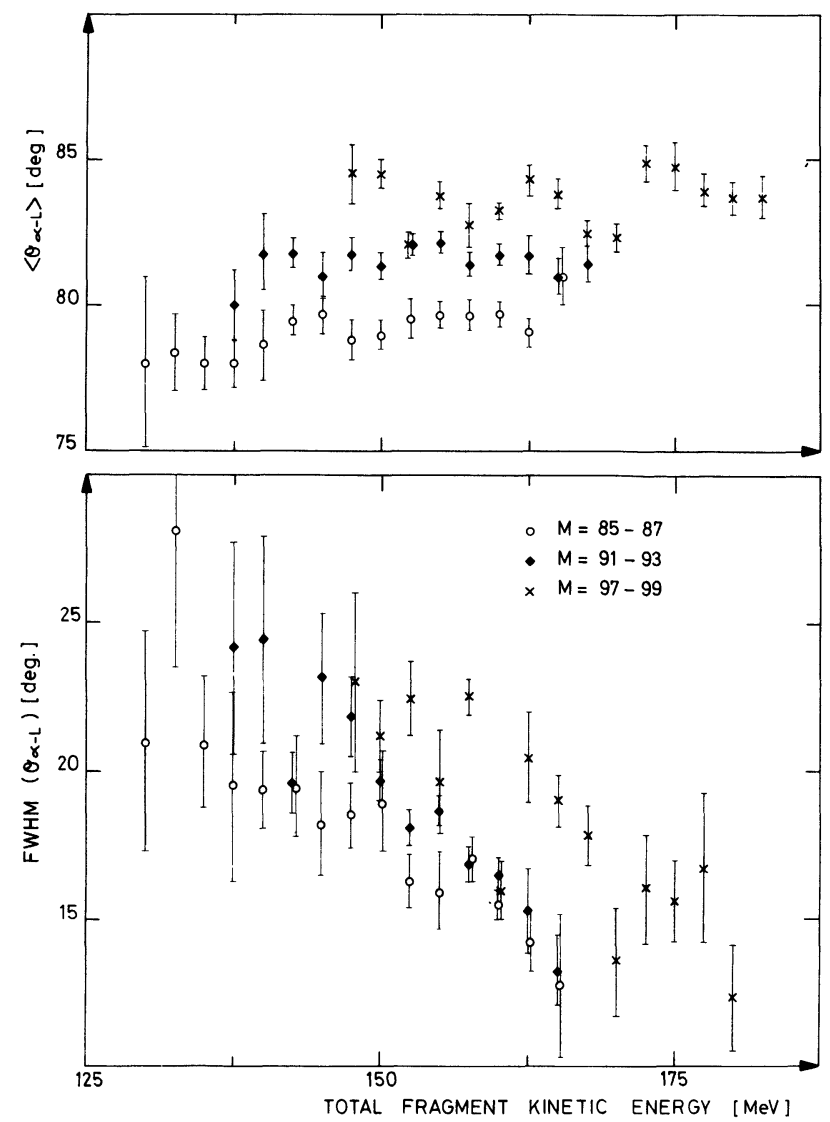

FIG. 1. - Average angle $\left(\left\langle\theta_{\alpha-\mathrm{L}}\right\rangle\right)$ and angular width (FWHM) as a function of total fragment energy with the conditions that $E_{\alpha}>9.5 \mathrm{MeV}$ and $M_{\mathrm{L}}=85-87 \mathrm{amu}(\mathrm{O})$, or $M_{\mathrm{L}}=91-93 \mathrm{amu}(\diamond)$, or $M_{\mathrm{L}}=97-99 \mathrm{amu}(\times)$.

the energy conservation relation :

$$
E_{\mathrm{K}}+E_{\alpha}=C+E_{\mathrm{K}_{0}}+E_{\alpha_{0}}
$$

can be written in a reasonable approximation as follows :

$$
\sigma^{2}\left(E_{\mathbf{K}}\right)=\sigma^{2}(C)+\sigma^{2}\left(E_{\mathbf{K}_{0}}\right)+2 C_{0} V\left(C, E_{\mathbf{K}_{0}}\right) .
$$

Here $C$ is the Coulomb potential energy of the fragments and is sensitive to their deformations. Let us consider two extreme situations :

i) First we assume that the spread in $E_{\mathrm{K}_{0}}$ is much larger than the spread in the Coulomb energy. In this case there is a one-to-one correspondence between $E_{\mathrm{K}}$ and $E_{\mathbf{K}_{0}}$. The fragment charge centre distance is then almost constant as is the dispersion in the initial position of the $\alpha$-particle. The faster the fragments separate, the less the $\alpha$-particle will be focused, thus leading to a broadening of the angular distributions as $E_{\mathrm{K}}$ increases. This is contrary to our experimental observations.

ii) Secondly, we now suppose $E_{\mathbf{K}_{0}}$ to be a constant, then $\sigma\left(E_{\mathrm{K}}\right) \simeq \sigma(C)$; in this case the higher values of $E_{\mathrm{K}}$ will expressed shorter distances between the fragment charge centres and hence more compact configu- 
rations, and consequently a narrower distribution of the initial positions for the emission of $\alpha$-particles. As the final emission angle is strongly determined by the initial position along the fragment axis, this extreme model predicts the same qualitative variation as observed experimentally.

In conclusion, the experimental results presented above tend to indicate that the dispersion of the total fission fragment kinetic energy results mainly from the fluctuations of the scission shapes (stretching modes) rather than from the distribution of the prescission kinetic energy which is certainly rather low.
This conclusion would mean that the features of the $\alpha$-accompanied fission are not contradictory to the models based on a quasi-statistical equilibrium among the collective degrees of freedom at scission $[11,12]$ as discussed and justified in terms of fission bands by Nörenberg [12].

Acknowledgments. - We are grateful to S. Bjornholm, M. Brack, K. Dietrich and P. Schuck for fruitful discussions. We are indebted to $\mathrm{M}$. Brack for reading the manuscript.

\section{References}

[1] Boneh, Y., Fraenkel, Z. and Nebenzahl, I., Phys. Rev. 156 (1967) 1305.

[2] Tsuji, K., Kataze, A., Yoshida, Y., Katayama, T., Toyofuku, F. and Yamamoto, H., Proc. 3rd Symp. on the physics and chemistry of fission (Rochester, 1973, Vienna) p. 405.

[3] Fluss, N. J., Kaufman, S. B., Steinberg, E. P. and Wilkins, B. D., Phys. Rev. C 7 (1973) 353.

[4] Piasecki, E. and Blocki, J., Nucl. Phys.' A 208 (1973) 381.

[5] Nix, J. R., Nucl. Phys. A 130 (1969) 241.

[6] Davies, K. T. R., Sierk, A. J., Nix, J. R., Phys. Rev. C 13 (1976) 2385.
[7] Rajagopalan, M. and Thomas, T. D., Phys. Rev. C 5 (1972) 2064.

[8] Gavron, A., Phys. Rev. C 11 (1975) 580.

[9] Fraenkel, Z., Phys. Rev. 156 (1973) 1283.

[10] Mehta, G. K., Poitou, J., Ribrag, M. and SignarbieuX, C., Phys. Rev. C 7 (1973) 373.

[11] Wilkins, B. D., Steinberg, E. P. and Chasman, R. R., Phys. Rev. C 14 (1976) 1832.

[12] Nörenberg, W., Proc. 2nd Symp. on physics and chemistry of fission Vienna (IAEA, Vienna, 1969), p. 51. 